\title{
Hidden Dimensions Unfurled
}

\section{Jon Kabat-Zinn ${ }^{1}$}

Published online: 25 June 2020

(C) Jon Kabat-Zinn 2020

It strikes me that the metaphor of hidden dimensions that have somehow not "unfurled" has practical applications in our lives. If physicists can think seriously in such strange ways, perhaps we all might as well, and thereby take a closer look at what is right beneath our noses.

For we might say that there are multiple dimensions in our own lives that are tightly curled up within us and for whatever reasons have not had the opportunity to unfurl, at least so far. If they did, perhaps it would come as quite a big bang in our own lives. Many stories speak of revelation and clarity in the meditative traditions in just that way, as sudden "explosions" of insight. They are hardly stranger than what science has been cooking up for us.

One such hidden dimension would be the present moment. The present moment is always right here, yet more often than not it is not apparent to us and therefore, practically speaking, unavailable - that is, we cannot avail ourselves of it. Its rich dimensionality is hidden and unknown in the press of our preoccupations with getting somewhere else, to a better moment or an end-result, speeding through the present without noticing it or that we are always in it, there being literally no place else to go or to be, no other time to occupy-unless we lose our minds and forget our hearts.

Might this dimension that is the present moment unfurl for us? It might. It might.

What would it take? How about stopping, looking, and listening? How about coming to our senses?

Earlier on (see Book 2, "Being Seen" and Book 3, "Attaining Place"), we dropped in on T. S. Eliot's sumptuous

Excerpted from Mindfulness for All: The Wisdom to Transform the World by Jon Kabat-Zinn. Copyright @ 2019 Jon Kabat-Zinn. Published by Hachette Books. All Rights Reserved.

Jon Kabat-Zinn

mindfulness@umassmemorial.org

1 Center for Mindfulness, University of Massachusetts Medical School, 55 Lake Avenue North, Worcester, MA 01605, USA banquet in the Four Quartets and helped ourselves to the dessert. Still, it may take some time, if we have the stomach for it, to digest those immortal lines:

Not known because not looked for,

But heard, half-heard in the stillness

Between two waves of the sea.

Quick, now, here, now always,

A condition of complete simplicity

(Costing not less than everything)

The power and profundity of our own embodied wakefulness embedded within the present moment are inconceivable, just as inconceivable for us as the huge energy of the vacuum or the tininess of un-unfurled dimensions deep inside our atoms or nested within the fabric of spacetime itself. In the case of the present moment, there is no way to believe in it, and no need to. One need only experience it and see for oneself how it might add back a dimension to living that accords us other degrees of freedom as well, whole new realms and ways to inhabit our lives and our world for the brief moments we are here that sum so quickly to what we call a lifetime and that are so easily missed. That is a banquet we are all called to, a repast where, moment by moment, you are invited, as Derek Walcott so beautifully put it, to: "Sit. Feast on your life."

Publisher's Note Springer Nature remains neutral with regard to jurisdictional claims in published maps and institutional affiliations. 